\title{
Adverse childhood events and risk of diabetes onset in the 1979 National longitudinal survey of youth cohort
}

E. Anne Lown ${ }^{1 *}$, Camillia K. Lui ${ }^{2}$, Kate Karriker-Jaffe ${ }^{2}$, Nina Mulia², Edwina Williams², Yu Ye², Libo Li², Thomas K. Greenfield ${ }^{2}$ and William C. Kerr ${ }^{2}$

\begin{abstract}
Background: Type 2 diabetes is a major public health problem with considerable personal and societal costs. Adverse childhood experiences (ACE) are associated with a number of serious and chronic health problems in adulthood, but these experiences have not been adequately studied in relation to diabetes in a US national sample. The association between ACE and poor health can be partially explained by greater risky health behaviors (RHB) such as smoking, heavy alcohol use, or obesity. Few studies have examined ACE in relation to adult onset Type 2 diabetes mellitus (T2DM) taking into account the role of RHB. Using longitudinal data from a representative US population sample followed over 30 years, this study examines the impact of ACE on the risk of diabetes onset.

Methods: Data from the 1982 to 2012 waves of the 1979 National Longitudinal Survey of Youth were analyzed, spanning ages 14 to 56. Bivariate and discrete-time survival models were used to assess the relationships between ACE and RHB including smoking, alcohol use, and obesity, and subsequent onset of diabetes.

Results: T2DM was reported by almost $10 \%$ of participants. Over $30 \%$ of women and $21 \%$ of men reported $2+$ ACE events. Women reporting 2-3 or 4+ ACE events were more likely to develop diabetes with the mean number of ACE events being greater in those with diabetes compared to without (1.28 vs.1.05, $p<.0001)$. For men there was no significant association between ACE and diabetes onset. For women, ACE was associated with heavy drinking, current smoking, and obesity. For men, ACE was associated with being underweight and daily smoking. In multivariate discrete-time survival models, each additional ACE increased risk of T2DM onset $\left(\mathrm{OR}_{\mathrm{adj}}=1.14 ; 95 \% \mathrm{Cl}\right.$ 1.02-1.26) for women but not for men. The relationship in women was attenuated when controlling for body mass index (BMI).

Conclusion: ACE predicted diabetes onset among women, though this relationship was attenuated when controlling for BMI. Being overweight or obese was significantly more common among women with a history of $A C E$, which suggests BMI may be on the pathway from ACE to diabetes onset for women.
\end{abstract}

Keywords: Type 2 diabetes mellitus, Adverse childhood events, Alcohol, Tobacco, Body mass index, Obesity

\footnotetext{
* Correspondence: Anne.Lown@ucsf.edu

${ }^{1}$ Department of Social and Behavioral Sciences, School of Nursing, University

of California, 3333 California Street, San Francisco, CA 94118, USA

Full list of author information is available at the end of the article
}

(c) The Author(s). 2019 Open Access This article is distributed under the terms of the Creative Commons Attribution 4.0 International License (http://creativecommons.org/licenses/by/4.0/), which permits unrestricted use, distribution, and reproduction in any medium, provided you give appropriate credit to the original author(s) and the source, provide a link to the Creative Commons license, and indicate if changes were made. The Creative Commons Public Domain Dedication waiver (http://creativecommons.org/publicdomain/zero/1.0/) applies to the data made available in this article, unless otherwise stated. 


\section{Background}

Adverse childhood experiences (ACE) are linked to many serious adult health conditions including cancers [1-3], cardiovascular disease or hypertension [2, 4, 5], diabetes [6-9], substance use [2], mental illness [10], disability [11], premature death [12, 13], and significantly greater health care costs [14]. Exposure to ACE can be a long-term determinant of poorer health $[15,16]$. ACEs impact later health through biological processes, psychiatric and physical health problems, psychosocial and developmental impacts, and factors related to age and late-life stressors [17].

Type 2 diabetes mellitus (T2DM) is the seventh leading cause of death in the United States (US) [18], affecting almost 29 million Americans [18] and costing the US $\$ 245$ billion in direct and indirect costs [19]. T2DM is the most prevalent form of diabetes, accounting for $90-95 \%$ of diabetes cases in the US [20]. Poorly controlled T2DM can lead to serious health problems including cardiovascular disease (the number one cause of death), lower-limb amputation, blindness, and kidney failure [19]. Careful management of T2DM is critically important in slowing or reversing the course of the disease. T2DM management often focuses on lifestyle interventions such as promoting healthy diet, exercise, losing excess weight, and taking medications.

In the landmark ACE study carried out at Kaiser Permanente in San Diego, CA [2], participants reporting ACE events were more likely to have T2DM. This finding was replicated in subsequent studies [6-9], including a general population, a cross-sectional community survey carried out in ten countries [10] and a large representative sample from ten US states and Washington, DC [7]. A meta-analysis representing 87,000 participants [21] and a systematic review including ten studies (involving population- and community-based cohorts) and over 200,000 people [22] also showed greater risk for T2DM or the development of metabolic abnormalities among respondents reporting ACE. One systematic review described a threshold response in several studies between ACE and T2DM, but the authors noted no clear dose response relationship [23]. This threshold effect also emerged in a cross-sectional study, where 4+ ACE was associated with T2DM, but fewer ACEs were not [23].

Previous research has examined specific ACEs that may raise the risk for T2DM. An Alameda County Study followed a cohort for 34 years and described increased risk for T2DM among those with childhood poverty, especially among women [24]. The Nurse's Health Study examined 67, 853 women and described lifetime physical or sexual abuse as a predictor of T2DM, noting the relationship was partially explained by high BMI among abused women [25].
Previous studies have documented the strong influence of ACE on risky health behaviors (RHBs) in general [26-28], and on obesity [29-35], tobacco use [36-38] and alcohol use [39, 40] specifically. Most studies do not adjust for obesity when examining the relationship between ACE and T2DM [6, 7], with a few exceptions where inclusion of BMI attenuated this relationship [9]. In the aforementioned systematic review [9], the relationship between ACE and T2DM was attenuated in four studies when adjusting for adult poverty and obesity [35, 41-43]. An improved understanding of the complex relationships between adult health behaviors and childhood events has the potential to help patients and providers manage and prevent T2DM.

While some studies describe ACE in relation to the development of T2DM over the life course [24, 25], more research is needed to better characterize a wide range of health behaviors (obesity, tobacco use, and alcohol use) over time. These behaviors may be related to both ACE and poor health outcomes. Previous studies have not controlled for risk factors such as adult poverty, minority race/ethnicity, and educational attainment. The current study aimed to address these gaps by using data from a nationally-representative panel sample starting in adolescence and spanning 38 years. The National Longitudinal Survey of Youth collected information on childhood adverse events, risky health behaviors and diabetes (among other health problems) in a diverse sample of men and women. We expected that ACE would be associated with onset of T2DM, and that the relationship would be partially-explained by health risk behaviors, including obesity, and alcohol use.

\section{Methods \\ Study population}

The National Longitudinal Survey of Youth 1979 (NLSY79) is an ongoing study of US individuals born between 1957 and 1964, selected using a stratified, clustered sampling design, that is representative of the non-institutionalized, non-military population of youth ages 14 to 21 in 1979 . The initial sample included 3,174 Blacks, 2,002 Hispanics, and 7,510 nonBlack/non-Hispanic participants who were interviewed annually between 1979 and 1994 and then every 2 years since 1994. The baseline response rate from NLSY79 was $90 \%$; retention rates were $80 \%$ or higher during 16 subsequent assessments but have declined to $71 \%$ (77\% excluding decedents) in recent assessments [44]. The current sample includes NLSY79 participants who provided data on at least 4 ACE events and on their T2DM status $(N=8,377)$. 


\section{Measures \\ Diabetes}

The dependent variable is onset of T2DM. NLSY79 participants completed a detailed health module after they turned 40, and again after they turned 50. Participants were asked, "Have you ever had, or has a doctor ever told you that you have diabetes or high blood sugar?" If they said yes, participants then reported the month and year of onset. Age of diabetes onset was calculated based on respondents' month and year of birth (provided at the baseline 1979 survey). Included diabetes cases were restricted to onset at age 18 and older.

\section{Adverse childhood experiences (ACE)}

In the 2012 survey, participants were asked a retrospective set of questions about events/experiences that occurred in childhood (before age 18). We identified the following ACEs: parental death, adverse living situation, living with a mentally ill person, living with a problem drinker, and being physically abused as a child. An adverse living situation between the ages of $0-18$ was defined as not living with two biological parents, living with grandparents or foster parents, or living in an orphanage or group home. Living in poverty at the baseline survey in 1979 was also included as an adverse event. The primary ACE measure was the total number of ACE events recorded (range: 0-6). However, in some analyses we used ACE binary indicators of two or more (2+), 3+ and 4+ ACE events compared to 0-1 event, since such threshold measures were consistent with prior studies $[36,45]$.

\section{Risky health behaviors}

Alcohol use Respondents were asked about their alcohol use in 1982-1985, 1988, 1989, 1994, 2002, and every other year from 2006 to 2012 . We created a time-varying measure of past month alcohol consumption. For years 1982-85, total volume was based on past week consumption of wine, beer and spirits. For 1988-2012, total volume was based on past month usual quantity and frequency for all beverages combined. To account for these measurement differences, weekly volume for 1982-1985 was adjusted downward, and monthly volume for 19882012 was adjusted upward, as described elsewhere [46]. We then created categories of total volume: zero drinks, low volume (less than or equal to 14 drinks per week for men or 7 drinks per week for women, according to national low-risk guidelines), risky drinking (more than 14 drinks but less than 28 drinks per week for men or more than 7 drinks and less than 14 drinks per week for women), and high volume (more than 28/14 drinks per week for men/women) [47]. Finally, to address concerns about appropriate non-drinking groups in prior alcohol- related health studies $[48,49]$, we further divided the no alcohol group into lifetime abstainers and no current alcohol use/former drinkers, as described elsewhere [49]. The low volume drinking group is the reference.

Smoking A set of smoking questions was asked in 1992, 1994, 1998, 2008, 2010, and 2012, including the age when participants started to smoke daily, current daily smoking (yes/no), and cigarettes smoked per day. Summarizing the available data, we created an age of onset of daily smoking and carried it forward from that age, and then grouped smoking status for each year into never daily smoker, former daily smoker, and current daily smoker and referred to in the manuscript as never, former, and current smoker.

Obesity Height was reported in 1981, 1982, 1983, 1985, 2006, 2008, 2010, and 2012. Weight was reported in 1981, 1982, 1985-86, 1988-1990, and every other year from 1992 to 2012. We carried forward height to calculate body mass index (BMI) scores for each available weight year. We calculated BMI as reported by weight in pounds divided by the square of height and then multiplied by a conversion factor of 703 [50]. BMI was coded into underweight $(<18.5)$, normal (18.5-24.9), overweight (25-29.9), and obese $(>=30)$, consistent with current recommendations [50].

Covariates We include sex (male and female), foreignor US-born, and self-reported race/ethnicity: White (reference group), Black, Hispanic, and 'Other racial/ethnic groups' (combined, including Asian, Hawaiian, and Pacific Islander, and American Indian). Age was calculated based on interview month and year and birth month and year. Educational attainment by age 25 was coded into less than high school diploma or equivalent, high school graduate, some college, and college degree or more.

We include repeated measures of poverty status (yes/ no), marital status (never married, married, separated, divorced, widowed), employment status (unemployed, employed, out of the labor force, active military), and whether the respondent has children (yes/no). These measures were available at each survey year.

\section{Statistical analyses}

The analytic sample included those who had data from the 2012 retrospective ACE questions and had available data on T2DM status in the $40+/ 50+$ health modules. First, we investigated bivariate relationships between the primary predictors (number of ACE events, RHBs) and the outcome (T2DM). We conducted sensitivity analyses to examine both a total ACE score and cut-points of 2+, $3+$ or $4+\mathrm{ACE}$ events versus fewer ACE events (i.e. ACE 
$3+$ vs. $0-2$ ). Testing of multiple cut-points is common in the ACE literature [2, 12, 36, 37, 45, 51-55].

Next, discrete-time survival models were used to model the onset of T2DM. Risk for T2DM starts in 1982, when participants were between the ages of 18 and 25. For those who reported the onset of T2DM before or on 2012 (when ages range from 48 to 55), their risk for T2DM ends in the year the event occurred. For all other participants, the risk period ended in the year when they reached 2012, which was the last survey year available (censoring). To model T2DM risk, time-invariant covariates such as foreign-born and race/ethnicity remained the same across time. Time-varying covariates such as alcohol consumption and employment were first created for the survey years and then were carried forward for the year(s) without interviews, until new data were available from a subsequent interview.

Our discrete-time survival model was implemented by a pooled logistic regression model [56] treating each reconstructed person-year as an observation. To avoid instability of estimation, the linear and quadratic terms for time (defined as the number of years from 1982) were added into our discrete-time survival model with the other time-variant and invariant covariates. No formal mediation testing was conducted given the categorical nature of the RHBs. Rather we implemented a series of models first adjusting for ACE and covariates (Model 1), then examining changes in ACE coefficient after adding in BMI (Model 2), and again after adding in alcohol and smoking (Model 3). Separate models were estimated for men and women and for White, Black, and Hispanic respondents (also stratified by sex). For the NLSY, survey weights are available for each year to adjust the sample to its original sampling frame, to be representative of US youth demographics in 1979, and account for attrition. All analyses were conducted in Stata version 14.2.

\section{Results}

\section{Sample characteristics}

Table 1 shows sample characteristics stratified by sex. Females constitute roughly $52 \%(N=4,328)$ of the sample. Prevalence of diabetes was approximately $10 \%$ for both women and men in this sample. Diabetes onset ranged from age 18 to age 52 . Only two cases of diabetes were diagnosed in participants who were aged 18-20, ( $0.2 \%$ of all diabetes cases). Given that $90 \%$ of all diabetes cases are T2DM, and the fact that the vast majority of Type 1 diabetes is diagnosed in young people age 115 , the authors have made the assumption that most all diabetes cases in this study are T2DM [57]. The most commonly reported ACE for both men and women was growing up living in a non-traditional situation with 35.7 and $31.7 \%$ respectively. In 1982 , the mean participant age was 21 years old. The sample was predominantly
White (61\% for females and 64\% for males). Between 12 and $14 \%$ reported less than a high school education and $21 \%$ reported college or more. Almost one-third of females (30\%) reported two or more ACEs compared to $21 \%$ of males. Poverty was experienced by $14 \%$ of female and $10 \%$ of male participants at some point in the course of the study.

\section{Bivariate relationships}

In evaluating the specific ACE items, (Table 2) childhood poverty and parental death were significantly associated with T2DM (OR crude $1.54 ; 95 \%$ CI 1.18, 2.01) and (OR crude 2.18 ; $95 \% \mathrm{CI}, 1.50,3.18)$ respectively. Women reporting 2 ACEs and 4+ ACEs were significantly more likely to have T2DM compared to those who reported fewer ACEs. Women with T2DM had significantly higher mean ACE scores compared to women without T2DM, (1.28 vs. 1.05, $p<.0001)$. Among men, T2DM was associated with having $4+$ ACEs, $\left(\mathrm{OR}_{\text {crude }}=2.51 ; 95 \% \mathrm{CI} 1.12,5.63\right)$ but not with any individual ACE items.

Overweight and obese women had higher ACE scores compared to normal weight women. For men, the mean number of ACEs was significantly greater for those who were underweight compared to overweight or obese BMI categories (Table 3). For women, the mean number of ACEs was significantly greater for high volume, former drinkers, and lifetime abstainers compared to low volume drinkers. Mean ACE events also were greater for women who were current smokers compared to never or former smokers. Men who were current smokers had greater mean ACEs compared to former and never smokers.

Figure 1 shows increasing BMI with age (as expected), with the total BMI being significantly higher among women who reported $2+$ ACE (a) and overweight status being reached at a younger age among those with $2+$ ACE (mean age 29) compared to those with $<2$ ACE. Those with $<2$ ACE became overweight later (mean age 33). Among men, BMI was not different by $2+$ ACE status (b).

\section{Survival models}

T2DM onset was predicted using discrete-time survival models controlling for time-invariant and time-varying covariates in Model 1 (Total Effect Model), with the addition of BMI adjustments in Models 2 (Direct Effects $\mathrm{BMI}_{\mathrm{adj}}$ ) and all 3 RHBs in Model 3 (Direct Effects$\mathrm{RHB}_{\text {adj }}$ (Table 4).

Among women, in the Total Effect, Model 1, mean ACE score significantly predicted $\mathrm{T} 2 \mathrm{DM}$ onset $\left(\mathrm{OR}_{\mathrm{adj}}=\right.$ 1.14; 95\% CI 1.02, 1.26)). Adjustment for BMI and all three RHBs added in Models 2 and 3 reduced the effect size between ACE and T2DM. In model 2-Direct Effects- $\mathrm{BMI}_{\mathrm{adj}}, \mathrm{BMI}$ was added, resulting in a slight 
Table 1 Sample characteristics of NLSY79 cohort

\begin{tabular}{|c|c|c|c|c|}
\hline \multirow{2}{*}{$\begin{array}{l}\text { Weighted \% (N) } \\
\text { Diabetes }\end{array}$} & \multicolumn{2}{|c|}{$\begin{array}{l}\text { Female } \\
(n=4,328)\end{array}$} & \multicolumn{2}{|c|}{$\begin{array}{l}\text { Male } \\
(n=4,049)\end{array}$} \\
\hline & $9.70 \%$ & $(431)$ & $10.2 \%$ & (367) \\
\hline Age of Diabetes Onset (Mean Years) & 43.5 & & 45.3 & \\
\hline \multicolumn{5}{|l|}{ Time-Invariant Variables } \\
\hline \multicolumn{5}{|l|}{ Adverse Childhood Events } \\
\hline Childhood Poverty & $14.3 \%$ & (960) & $12.6 \%$ & (767) \\
\hline Parental Death & $8.1 \%$ & (353) & $7.9 \%$ & (298) \\
\hline Non-Traditional Living Situation & $35.7 \%$ & $(1,457)$ & $31.7 \%$ & $(1,172)$ \\
\hline Lived w/Mentally III Person & $11.3 \%$ & (358) & $5.0 \%$ & (141) \\
\hline Lived w/Problem Drinker & $22.8 \%$ & (794) & $15.7 \%$ & (506) \\
\hline Physical Abuse & $16.8 \%$ & (621) & $12.7 \%$ & $(417)$ \\
\hline \multicolumn{5}{|l|}{$2+$ Ace Events } \\
\hline No & $69.6 \%$ & $(2,384)$ & $76.9 \%$ & $(2,378)$ \\
\hline Yes & $30.4 \%$ & $(1,342)$ & $21.1 \%$ & (954) \\
\hline Age in 1982 (Mean) & 20.72 & & 20.53 & \\
\hline \multicolumn{5}{|l|}{ Race/Ethnicity } \\
\hline White & $60.9 \%$ & $(1,477)$ & $63.5 \%$ & $(1,382)$ \\
\hline Black & $15.2 \%$ & $(1,125)$ & $14.3 \%$ & (983) \\
\hline Hispanic & $6.4 \%$ & (664) & $5.9 \%$ & (580) \\
\hline Other & $17.5 \%$ & (445) & $16.4 \%$ & (372) \\
\hline \multicolumn{5}{|l|}{ U.S. Born } \\
\hline Yes & $95.9 \%$ & $(3,479)$ & $96.2 \%$ & $(3,114)$ \\
\hline \multicolumn{5}{|l|}{ Education Attainment } \\
\hline Less than High School & $11.8 \%$ & (590) & $13.6 \%$ & $(621)$ \\
\hline High School & $44.9 \%$ & $(1,652)$ & $44.7 \%$ & $(1,509)$ \\
\hline Some College & $22.9 \%$ & (889) & $20.5 \%$ & $(661)$ \\
\hline College or more & $20.5 \%$ & (593) & $21.3 \%$ & (536) \\
\hline \multicolumn{5}{|l|}{ Time-Varying Variables (1982-2012) } \\
\hline Children (Mean) & 1.60 & & 0.90 & \\
\hline \multicolumn{5}{|l|}{ Poverty Status } \\
\hline No & $86.1 \%$ & & $89.7 \%$ & \\
\hline Yes & $14.0 \%$ & & $10.3 \%$ & \\
\hline \multicolumn{5}{|l|}{ Marital Status } \\
\hline Never Married & $22.3 \%$ & & $31.5 \%$ & \\
\hline Married & $58.4 \%$ & & $54.9 \%$ & \\
\hline Separated & $4.3 \%$ & & $2.9 \%$ & \\
\hline Divorced & $14.1 \%$ & & $10.5 \%$ & \\
\hline Widowed & $1.0 \%$ & & $0.2 \%$ & \\
\hline \multicolumn{5}{|l|}{ Employment Status } \\
\hline Employed & $75.3 \%$ & & $85.9 \%$ & \\
\hline Unemployed & $2.0 \%$ & & $2.9 \%$ & \\
\hline Out of Labor Force & $22.4 \%$ & & $8.8 \%$ & \\
\hline Active Services & $0.3 \%$ & & $2.5 \%$ & \\
\hline
\end{tabular}


Table 2 Odds ratio for adverse childhood events by diabetes status and mean number of ACE for men and women with diabetes

\begin{tabular}{|c|c|c|c|c|c|c|c|c|}
\hline & \multicolumn{4}{|c|}{$\begin{array}{l}\text { Female } \\
(n=3,726)\end{array}$} & \multicolumn{4}{|c|}{$\begin{array}{l}\text { Male } \\
(n=3,332)\end{array}$} \\
\hline & $\%$ & $n$ & OR & $95 \% \mathrm{Cl}$ & $\%$ & $\mathrm{n}$ & OR & $95 \% \mathrm{Cl}$ \\
\hline \multicolumn{9}{|l|}{ Childhood Poverty } \\
\hline No & $9.2 \%$ & (279) & & & $10.1 \%$ & (253) & & \\
\hline Yes & $13.6 \%$ & (136) & $1.54^{*}$ & $(1.18,2.01)$ & $10.6 \%$ & (89) & 1.05 & $(0.76,1.47)$ \\
\hline \multicolumn{9}{|l|}{ Parental Death } \\
\hline No & $8.9 \%$ & (373) & & & $10.3 \%$ & (331) & & \\
\hline Yes & $17.6 \%$ & $(56)$ & $2.18^{*}$ & $(1.50,3.18)$ & $9.0 \%$ & (35) & 0.86 & $(0.53,1.40)$ \\
\hline \multicolumn{9}{|l|}{$\begin{array}{l}\text { Non-Traditional } \\
\text { Living Situation }\end{array}$} \\
\hline No & $9.3 \%$ & (238) & & & $9.9 \%$ & (222) & & \\
\hline Yes & $10.4 \%$ & (180) & 1.13 & $(0.87,1.46)$ & $11.0 \%$ & (131) & 1.12 & $(0.84,1.49)$ \\
\hline \multicolumn{9}{|l|}{$\begin{array}{l}\text { Lived W/ } \\
\text { Mentally III Person }\end{array}$} \\
\hline No & $9.4 \%$ & (381) & & & $10.0 \%$ & (345) & & \\
\hline Yes & $11.5 \%$ & (49) & 1.24 & $(0.84,1.83)$ & $15.1 \%$ & (21) & 1.6 & $(0.92,2.80)$ \\
\hline \multicolumn{9}{|l|}{$\begin{array}{l}\text { Lived w/ } \\
\text { Problem Drinker }\end{array}$} \\
\hline No & $9.4 \%$ & (331) & & & $10.0 \%$ & (310) & & \\
\hline Yes & $10.4 \%$ & (99) & 1.11 & $(0.83,1.50)$ & $11.3 \%$ & (57) & 1.15 & $(0.80,1.65)$ \\
\hline \multicolumn{9}{|l|}{ Physical Abuse } \\
\hline No & $9.3 \%$ & (339) & & & $9.8 \%$ & (311) & & \\
\hline Yes & $11.5 \%$ & (89) & 1.27 & $(0.93,1.73)$ & $13.2 \%$ & (56) & 1.41 & $(0.96,2.07)$ \\
\hline \multicolumn{9}{|l|}{$\begin{array}{l}\text { Sum of Adverse } \\
\text { Childhood Events }\end{array}$} \\
\hline $0 \mathrm{ACE}$ & $7.9 \%$ & (116) & & & $9.8 \%$ & (148) & & \\
\hline $1 \mathrm{ACE}$ & $9.9 \%$ & (135) & 1.28 & $(0.93,1.76)$ & $9.7 \%$ & (104) & 0.99 & $(0.72,1.38)$ \\
\hline $2 \mathrm{ACE}$ & $11.4 \%$ & (104) & $1.50^{*}$ & $(1.06,2.12)$ & $10.8 \%$ & (73) & 1.12 & $(0.77,1.64)$ \\
\hline $3 \mathrm{ACE}$ & $10.3 \%$ & (43) & 1.34 & $(0.85,2.12)$ & $11.3 \%$ & (29) & 1.18 & $(0.67,2.06)$ \\
\hline $4+\mathrm{ACE}$ & $16.1 \%$ & (33) & $2.23^{*}$ & $(1.32,3.75)$ & $21.3 \%$ & (13) & $2.51^{*}$ & $(1.12,5.63)$ \\
\hline \multicolumn{9}{|l|}{$\begin{array}{l}\text { Mean Adverse } \\
\text { Childhood Events } \\
\text { by Diabetes } \\
\text { Prevalence }\end{array}$} \\
\hline & \multicolumn{4}{|c|}{ Diabetes-Female } & \multicolumn{4}{|c|}{ Diabetes-Male } \\
\hline & Yes & No & $P$-value & & Yes & No & P-value & \\
\hline Mean ACE Score & 1.28 & 1.05 & $<.0001$ & & 0.93 & 0.82 & 0.062 & \\
\hline
\end{tabular}

decrease in the effect size $\left(\mathrm{OR}_{\mathrm{adj}}=1.10 ; 95 \% \mathrm{CI} 1.00\right.$, 1.22) between ACE and T2DM and a reduction from significance to marginal significance $(p=0.06)$. BMI was a strong predictor for $\mathrm{T} 2 \mathrm{DM}$ in underweight $\left(\mathrm{OR}_{\mathrm{adj}}=\right.$ $3.87 ; 95 \%$ CI $1.73,8.67)$, overweight $\left(\mathrm{OR}_{\mathrm{adj}}=2.89 ; 95 \%\right.$ CI 1.93, 4.35), and obese $\left(\mathrm{OR}_{\mathrm{adj}}=8.97 ; 95 \%\right.$ CI 6.32, 12.74) groups compared to the normal group. In Model 3 Direct Effects- $\mathrm{RHB}_{\mathrm{adj}}$, female lifetime abstainers showed increased risk for T2DM $\left(\mathrm{OR}_{\mathrm{adj}}=1.56 ; 95 \% \mathrm{CI}\right.$ 1.07, 2.27) compared to their low-risk drinking counterparts. ACE effect size was reduced $\left(\mathrm{OR}_{\mathrm{adj}}=1.11\right.$; $95 \%$ CI 1.00, 1.23) and remained significant, $p=0.05$ ). Smoking did not predict T2DM onset. Other significant risk factors for T2DM onset among women include older age, living in poverty, being out of the labor force, attending only some college, and being Hispanic or Black compared to being White. Being widowed was protective.

Among men, ACE did not predict T2DM onset in any models. In Model 2- Direct Effects-BMI $\mathrm{Bdj}_{\text {adj }}$ being 
Table 3 Mean adverse childhood events by health behavior

\begin{tabular}{|c|c|c|c|c|c|c|}
\hline & \multicolumn{3}{|c|}{ Female } & \multicolumn{3}{|l|}{ Male } \\
\hline & Mean & $95 \% \mathrm{Cl}$ & $p$-value & Mean & $95 \% \mathrm{Cl}$ & $p$-value \\
\hline \multicolumn{7}{|l|}{ Body Mass Index } \\
\hline Underweight & 1.05 & $(1.02,1.12)$ & $<0.001$ & 1.01 & $(0.91,1.11)$ & $<0.001$ \\
\hline Normal Weight & 0.99 & $(0.98,1.01)$ & & 0.84 & $(0.83,0.86)$ & \\
\hline Overweight & 1.06 & $(1.05,1.09)$ & & 0.80 & $(0.79,0.81)$ & \\
\hline Obese & 1.20 & $(1.18,1.22)$ & & 0.85 & $(0.84,0.87)$ & \\
\hline \multicolumn{7}{|l|}{ Alcohol Use } \\
\hline Lifetime Abstainer & 1.07 & $(1.06,1.11)$ & $<0.001$ & 0.75 & $(0.72,0.78)$ & $<0.001$ \\
\hline Former Drinker & 1.15 & $(1.14,1.17)$ & & 0.97 & $(0.96,0.99)$ & \\
\hline Low $\leq 14 / 7$ per $w k$ & 0.98 & $(0.97,0.99)$ & & 0.76 & $(0.75,0.77)$ & \\
\hline Risky (> 14/7 per week) & 1.02 & $(0.99,1.05)$ & & 0.84 & $(0.82,0.87)$ & \\
\hline High Volume (> 28/14 per week) & 1.22 & $(1.18,1.28)$ & & 0.97 & $(0.94,1.01)$ & \\
\hline \multicolumn{7}{|l|}{ Smoking Status } \\
\hline Never Daily Smoker & 0.86 & $(0.85,0.88)$ & $<0.001$ & 0.70 & $(0.69,0.71)$ & $<0.001$ \\
\hline Former Daily Smoker & 1.17 & $(1.16,1.20)$ & & 0.91 & $(0.89,0.93)$ & \\
\hline Current Daily Smoker & 1.26 & $(1.25,1.28)$ & & 0.98 & $(0.97,0.99)$ & \\
\hline
\end{tabular}
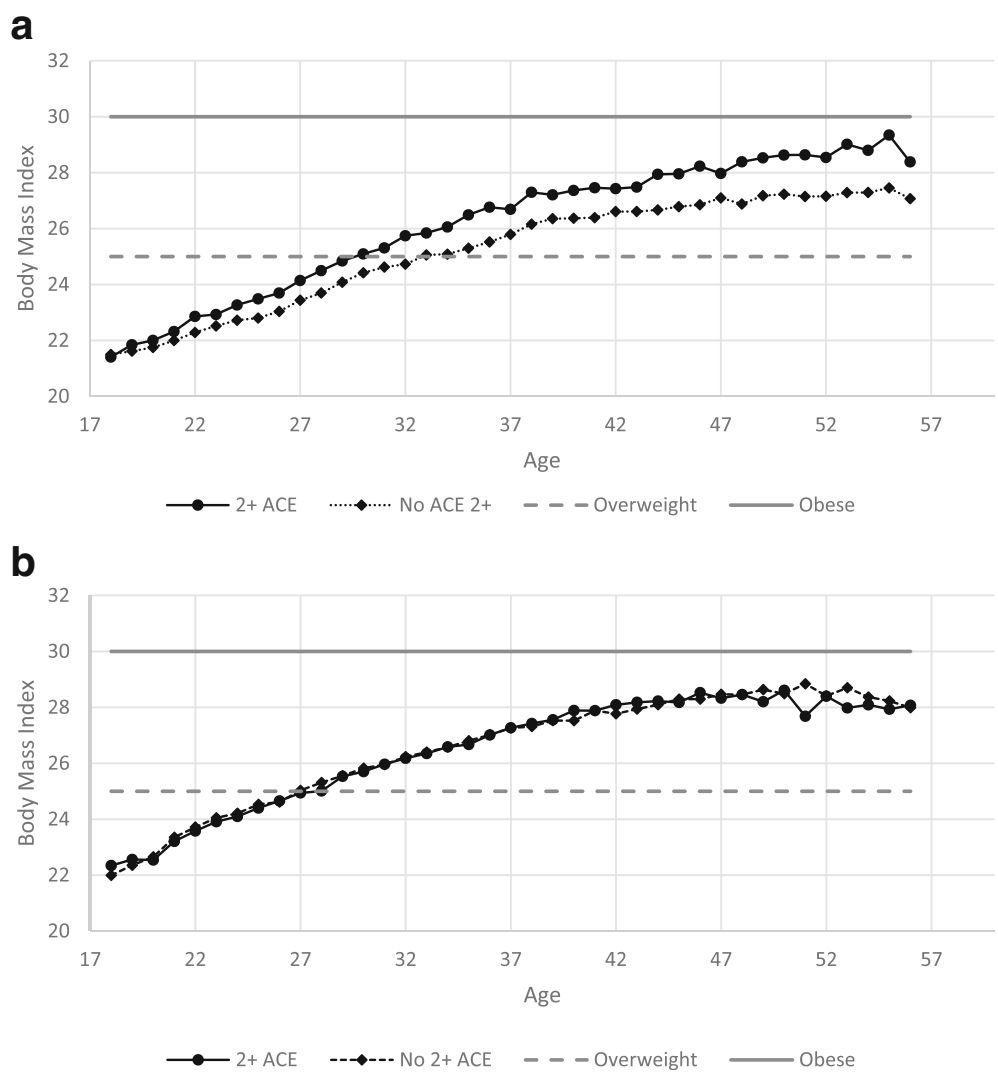

Fig. 1 a Female Body Mass Index by Age and Adverse Childhood Events. b Male Body Mass Index by Age and Adverse Childhood Events 
Table 4 Discrete-time models of diabetes onset, NLSY79

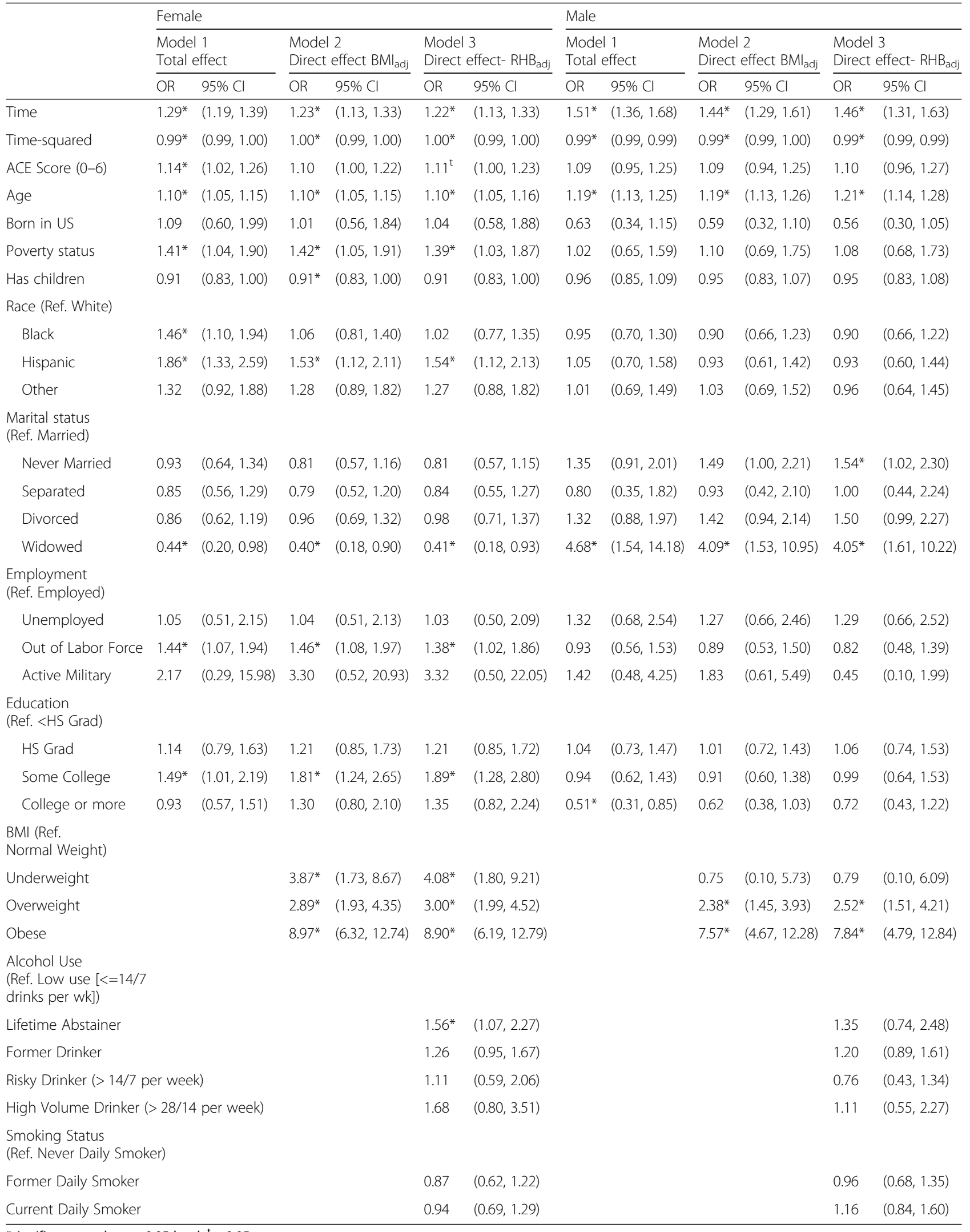

${ }^{*}$ significance at the $p<0.05$ level, ${ }^{\mathrm{t}}=0.05$ 
Table 5 Race and sex-stratified models of diabetes onset, NLSY79 - model showing direct effect- RHBadj

\begin{tabular}{|c|c|c|c|c|c|c|c|c|}
\hline & \multicolumn{8}{|c|}{ Female } \\
\hline & \multicolumn{2}{|l|}{ White } & \multicolumn{2}{|l|}{ Black } & \multicolumn{2}{|l|}{ Hisp } & \multicolumn{2}{|l|}{ Other } \\
\hline & $\overline{\mathrm{OR}}$ & $p$-value & OR & $p$-value & OR & $p$-value & $\overline{\mathrm{OR}}$ & $p$-value \\
\hline Time & $1.22^{*}$ & 0.002 & $1.31^{*}$ & 0.000 & $1.34^{*}$ & 0.001 & 1.14 & 0.131 \\
\hline Time-squared & $1.00^{*}$ & 0.012 & $0.99^{*}$ & 0.000 & $0.99^{*}$ & 0.001 & 1.00 & 0.176 \\
\hline ACE-Score (0-6) & 1.10 & 0.221 & 1.04 & 0.668 & 1.05 & 0.569 & 1.23 & 0.186 \\
\hline Age & $1.10^{*}$ & 0.014 & $1.12^{*}$ & 0.002 & $1.09^{*}$ & 0.046 & 1.10 & 0.209 \\
\hline Born in US & 0.95 & 0.927 & & & 1.46 & 0.159 & 0.44 & 0.258 \\
\hline In Poverty & 1.00 & 0.992 & $1.83^{*}$ & 0.006 & $1.80^{*}$ & 0.032 & $2.10^{*}$ & 0.041 \\
\hline Has children & 0.90 & 0.238 & $0.87^{*}$ & 0.025 & 0.87 & 0.168 & 1.03 & 0.783 \\
\hline \multicolumn{9}{|l|}{ Marital Status (Ref. Married) } \\
\hline Never Married & 0.76 & 0.398 & 0.80 & 0.323 & 0.77 & 0.452 & 1.17 & 0.775 \\
\hline Separated & $0.13^{*}$ & 0.006 & 0.97 & 0.911 & 1.22 & 0.592 & 1.57 & 0.471 \\
\hline Divorced & 1.21 & 0.445 & 1.00 & 0.998 & 0.73 & 0.303 & 0.65 & 0.366 \\
\hline Widowed & -- & -- & 1.06 & 0.918 & 0.59 & 0.473 & 0.32 & 0.231 \\
\hline \multicolumn{9}{|l|}{ Employment (Ref. Employed) } \\
\hline Unemployed & 1.32 & 0.653 & 1.12 & 0.771 & 0.46 & 0.439 & -- & -- \\
\hline Out of Labor Force & $1.62^{*}$ & 0.031 & $0.60^{*}$ & 0.029 & 1.38 & 0.172 & 1.73 & 0.167 \\
\hline In Active Forces & $8.61^{*}$ & 0.023 & -- & -- & -- & -- & -- & -- \\
\hline \multicolumn{9}{|l|}{ Education (Ref. <HS Grad) } \\
\hline HS Grad & 1.10 & 0.774 & 1.08 & 0.756 & 1.23 & 0.453 & 1.88 & 0.218 \\
\hline Some College & $2.32^{*}$ & 0.018 & 1.08 & 0.784 & $2.07^{*}$ & 0.032 & 2.10 & 0.239 \\
\hline College or more & 1.29 & 0.542 & 0.81 & 0.578 & 1.27 & 0.621 & 2.81 & 0.148 \\
\hline \multicolumn{9}{|l|}{ Alcohol Use (Ref low <=14/7 per wk) } \\
\hline Lifetime Abstainer & 1.77 & 0.054 & 0.96 & 0.885 & 1.44 & 0.294 & 3.09 & 0.086 \\
\hline Former Drinker & 1.19 & 0.449 & 1.20 & 0.352 & 0.67 & 0.187 & $2.35^{*}$ & 0.034 \\
\hline Risky Drinker (>14/7 per week) & 0.97 & 0.949 & 1.08 & 0.862 & 0.89 & 0.819 & 2.18 & 0.376 \\
\hline High Volume Drinker (>28/14 per week) & 2.43 & 0.055 & 0.87 & 0.824 & 2.26 & 0.144 & -- & -- \\
\hline \multicolumn{9}{|l|}{ Smoking Status (Ref. Never Daily Smoker) } \\
\hline Former Daily Smoker & 0.78 & 0.380 & 0.93 & 0.784 & 1.10 & 0.709 & 1.08 & 0.883 \\
\hline Current Daily Smoker & 0.95 & 0.841 & 0.87 & 0.535 & 1.15 & 0.649 & 0.96 & 0.934 \\
\hline \multicolumn{9}{|l|}{ BMI (Ref. Normal Weight) } \\
\hline Underweight & $4.48^{*}$ & 0.005 & 1.72 & 0.603 & -- & -- & 4.88 & 0.054 \\
\hline Overweight & $2.96^{*}$ & 0.000 & $2.99^{*}$ & 0.003 & $2.11^{*}$ & 0.036 & $3.57^{*}$ & 0.010 \\
\hline Obese & $10.25^{*}$ & 0.000 & $8.31^{*}$ & 0.000 & $7.95^{*}$ & 0.000 & $6.58^{*}$ & 0.000 \\
\hline Intercept & 0.00 & 0.000 & 0.00 & 0.000 & 0.00 & 0.000 & 0.00 & 0.000 \\
\hline
\end{tabular}

${ }^{*}$ significance at the $p<0.05$ level

overweight $\left(\mathrm{OR}_{\mathrm{adj}}=2.38 ; 95 \% \mathrm{CI} 1.45,3.93\right)$ or obese $\left(\mathrm{OR}_{\mathrm{adj}}=7.57 ; 95 \%\right.$ CI 4.67, 12.28), was a strong predictor of T2DM but the introduction of BMI did not alter the effect size between ACE and T2DM. Alcohol and smoking were not predictive of T2DM in Model 3-Direct Effects- RHB $_{\text {adj }}$.

Given the significant racial/ethnic differences in T2DM risk among women seen in Table 4 Model 1-Total Effect, we conducted exploratory analyses among women only, stratifying by race (Table 5). ACE was not a significant predictor of T2DM onset for White, Black, Hispanic or "Other" women. In all cases, being overweight or obese was a significant predictor for T2DM and tobacco and alcohol use were not significant predictors except in the case of "Other" women where former drinkers were more likely to have T2DM $\left(\mathrm{OR}_{\mathrm{adj}}=2.35, p=034\right)$. 


\section{Discussion}

The current study used nationally representative longitudinal data across 30 years to examine ACE in relation to T2DM onset after age 17, together with RHB. Previous literature has hypothesized that RHB, which are more common in people reporting ACE (i.e. high BMI, smoking, or heavy alcohol use), might explain increased risk for numerous poor health outcomes in those with an ACE. Many ACE-T2DM studies have not included RHB with some notable exceptions [25, 35, 42, 43], and to date, findings have focused on BMI as a risk factor. In the current study, with inclusion of a larger number of adult health behaviors, survival models provided confirmatory evidence that ACE predicts T2DM onset among women, even while controlling for other RHBs $(p=.05)$. This finding is consistent with previous studies [24], noting that physical or sexual abuse predicted T2DM and that the relationship, as in the present study, was partially explained by high BMI in the abused women [25]. While ACEs in the present study were associated with greater RHB, results suggest that BMI may remain the most important mechanism for the association between ACE and T2DM in women, one that also appears to contribute to racial/ethnic disparities in women's T2DM risk.

T2DM was associated with individual adverse events among women including childhood poverty, and parental death, as well as with $2+$ ACE events. Among men, 4+ ACE predicted T2DM in bivariate models only. In multivariate models, mean ACE score predicted T2DM onset in women, but not in men. Further analyses showed that RHBs, and BMI in particular, were higher among participants reporting 2+ ACE. When we accounted for these RHBs, ACE was more weakly associated with T2DM in women. Despite inclusion of additional behavioral risks, BMI emerged as the strongest predictor of T2DM onset, with women's lifetime abstention associated with a marginally increased risk.

Numerous studies including a Danish national cohort [58] and several meta-analyses [59-61] have described the protective effect of light to moderate drinking on T2DM, with some exceptions among women [61, 62]. Similar to these studies, the present study identified higher risk for T2DM among women lifetime abstainers compared to light drinkers, showing a protective effect for light drinking among women only. While studies have documented a beneficial effect of light alcohol use on T2DM onset, a large case-cohort study concluded that the increased risk was mostly explained by confounding factors, cautioning that people should not take up drinking with the hope that it could prevent T2DM [63]. A meta-analysis representing 1.9 million participants concluded that a reduction in risk among drinkers (increased risk in non-drinkers) was only apparent for women [61]. This finding was consistent with the present study where women lifetime abstainers had higher risk for T2DM (low drinking had a protective effect) even controlling for ACE and other confounders.

Smoking status showed a graded pattern of association with ACE where never smokers had the fewest ACE events and current smokers had the most events. This finding is consistent with other ACE studies [37]. While smoking has been shown to increase the risk for T2DM in previous studies $[64,65]$, in the present sample this relationship was not evident. Among people with T2DM smoking complicates medical management and increases health risks related to cardiovascular disease and peripheral neuropathies $[65,66]$.

The strong relationship between ACE and obesity found in women overall was present in each racial/ethnic group. This finding suggests that women of all backgrounds may be more likely to gain weight possibly as an internalizing attempt to cope with psychological stress or trauma following ACE $[9,67]$ where eating is an attempt to regulate emotions in the face of stress [68]. Weight gain may further contribute to T2DM risk [69]. Serious stress in childhood is known to compromise the hypothalamic-pituitary-adrenal axis and activate the sympathetic nervous system leading to difficulty with emotion regulation, obesity, and increase risk for metabolic syndrome [70].

Racial/ethnic disparities in women's T2DM risk were also documented in this sample, as in prior studies. Black women, known to be at greater risk for T2DM in general [24], showed higher risk for T2DM relative to white women when adjusting for ACE and demographic risk factors, but this difference disappeared after accounting for BMI. By contrast, Hispanic women's elevated risk for T2DM remained significant [71], albeit reduced, after accounting for BMI. While BMI cannot easily be separated out from access to healthy foods, outdoor physical activities, and socioeconomic status, the current study provides cautionary evidence that reducing BMI among Black and Hispanic women with a history of ACE may be important in preventing racial/ethnic disparities in T2DM, along with addressing additional factors thought to contribute to these disparities [72]. The present findings are consistent with previous studies where early childhood poverty, a factor closely related to poorer nutritional status, was a predictor for adult T2DM [6, 22]. Our results from race-stratified models suggest that for racial/ethnic minority women, the risk associated with childhood poverty could be further compounded by adult poverty, as the latter was a significant contributor to T2DM in racial/ethnic minority women. Previous research documenting an association between health behaviors and higher rates of T2DM can be explained, in part, by environmental factors such as 
poverty, crime, and segregated housing that are associated with poor access to healthy food and limited opportunities for physical activity [72-74].

The current study has a number of strengths including the large sample size, use of longitudinal data covering over 35 years starting while participants were adolescents, and inclusion of health behavior measures over time. In addition, the NLSY included the onset of several serious health outcomes including diabetes. This data provided a unique opportunity to examine the emergence of risk behaviors in the years following ACE and to track the onset of diabetes in relation to these health behaviors over time.

As with any study, there are some limitations. While a strength was use of time-varying measures of health behaviors such as drinking volume, another measures of alcohol use, binge drinking, that is commonly used, is not assessed here, thus findings are specific to the alcohol covariates used [75]. The exclusion of certain ACE questions, i.e., child emotional and sexual abuse, may mean that the available ACE variable was less severe than ACE variables used in other studies. Previous studies have found that childhood sexual abuse is a strong predictor for adverse health outcomes [76-78]. However, the present study did include childhood physical abuse. Child physical abuse was the only ACE event that was consistently related to all six serious chronic diseases studied, as reported in a ten country study, thus capturing a great deal of the variance in explaining subsequent harms from ACE [10]. Recent psychometric evaluations documented that use of a 2-item measure that includes parental alcohol and childhood emotional abuse items can correctly identify people with ACE experiences with 90\% sensitivity [79]. The omission of sexual and emotional abuse may result in an underestimate of the actual impact of adverse events on long-term health and diabetes. Some previous studies examined levels of ACE and noted a threshold effect after 4+ ACE [23]. This finding was confirmed for both women and men in the present study. The present study uses ACE as a continuous variable with levels ranging from 0 to 6 , allowing assessment of ACE as a gradient and avoiding results that can fluctuate between categories. Finally, NLSY questions about diabetes onset did not differentiate between Type 1 and Type 2 diabetes. However, Type 1 diabetes onset is rare above age 20. The current data included only $0.2 \%$ of diabetes cases that were age 20 or younger and $2.9 \%$ of cases were age 25 or below. Thus, results from the study are unlikely to be different in the unlikely event that some of these cases were type 1 diabetes. Finally, analyses that reported differences in effect sizes as an assessment of mediation rely on many assumptions as highlighted by Vanderweele [80, 81], (e.g., no interaction between exposure and mediator, no unmeasured confounding, no mediator-outcome confounding). Those assumptions are common to any kind of regressionbased mediation analyses. Violation of those assumptions may affect the interpretation of our results.

\section{Conclusion}

The present study describes a graded relationship between ACE and T2DM among women, with additional findings showing that the relationship may be strongly influenced by the higher risk for overweight and obese status among women with a history of ACE. To prevent T2DM among women at risk, it is recommended that women receive counseling to reduce their diabetes risk consistent with national recommendations [82-86] addressing physical activity, diet, and weight loss and recommendations that programs be tailored to address the needs of Black [87] and Hispanic women [88]. Additional screening for ACE should occur so that women with a history of ACE receive combined psychological counseling along with traditional diabetes prevention.

\section{Abbreviations \\ ACE: Adverse childhood experiences; BMI: Body mass index; NLSY79: The National Longitudinal Survey of Youth 1979; OR: Odds ratio; T2DM: Type 2 diabetes mellitus}

\section{Acknowledgements \\ None.}

\section{Authors' contributions}

Conception and design of the study: WCK, EAL, NM, KKJ. Statistical analysis: EW, CKL, LL. Manuscript preparation: EAL, CKL. Reviewed/edited and approved the manuscript: TKG, KKJ, WCK, CKL, LL, NM, YY, EW. Guarantor: EAL. All authors read and approved the final manuscript.

\section{Funding}

This work was supported by the U.S. National Institute on Alcohol Abuse and Alcoholism (NIAAA) at the National Institutes of Health $(\mathrm{NIH})$ [grant number R01 AA021448]. Content and opinions are those of authors and do not necessarily reflect official positions of NIAAA or $\mathrm{NIH}$.

\section{Availability of data and materials}

The data analyzed during the current study were drawn from the National Longitudinal Surveys public-use data for the 1979 cohort available at no cost via the Investigator website, (https://www.nlsinfo.org/investigator/pages/ login.jsp?p=timeout) an online search and extraction site that enables the user to review NLSY variables and create individual data sets. Information on the data is described here: https://www.bls.gov/nls/nlsy79.htm.

\section{Ethics approval and consent to participate}

The study was approved by the Public Health Institute IRB \#114-007. This present study used de-identified data from the household survey of the NLSY79. Participants from the NLSY79 reviewed the confidentiality and consent information sent in an advance letter. Participants were then asked for verbal consent to participate at the beginning of the interview. [https:// www.nlsinfo.org/content/cohorts/nlsy79/intro-to-the-sample/confidentialityinformed-consent/page/0/2].

Consent for publication

Not applicable.

Competing interests

The authors declare that they have no competing interests. 


\section{Author details}

'Department of Social and Behavioral Sciences, School of Nursing, University of California, 3333 California Street, San Francisco, CA 94118, USA. ${ }^{2}$ Alcohol Research Group, Public Health Institute, 6001 Shellmound Ave, Suite 450, Emeryville, CA 94608, USA.

Received: 6 September 2018 Accepted: 18 July 2019

Published online: 27 July 2019

\section{References}

1. Brown DW, Anda RF, Felitti VJ, Edwards VJ, Malarcher AM, Croft JB, et al. Adverse childhood experiences are associated with the risk of lung cancer: a prospective cohort study. BMC Public Health. 2010;10:20.

2. Felitti VJ, Anda RF, Nordenberg D, Williamson DF, Spitz AM, Edwards V, et al. Relationship of childhood abuse and household dysfunction to many of the leading causes of death in adults. The adverse childhood experiences (ACE) study. Am J Prev Med. 1998;14(4):245-58.

3. Kelly-Irving M, Lepage B, Dedieu D, Lacey R, Cable N, Bartley M, et al. Childhood adversity as a risk for cancer: findings from the 1958 British birth cohort study. BMC Public Health. 2013;13:767.

4. Su S, Wang X, Pollock JS, Treiber FA, Xu X, Snieder H, et al. Adverse childhood experiences and blood pressure trajectories from childhood to young adulthood: the Georgia stress and heart study. Circulation. 2015; 131(19):1674-81.

5. Su S, Jimenez MP, Roberts CT, Loucks EB. The role of adverse childhood experiences in cardiovascular disease risk: a review with emphasis on plausible mechanisms. Curr Cardiol Rep. 2015;17(10):88.

6. Bellis MA, Hughes K, Leckenby N, Hardcastle KA, Perkins C, Lowey H. Measuring mortality and the burden of adult disease associated with adverse childhood experiences in England: a national survey. J Public Health (Oxf). 2015;37(3):445-54.

7. Gilbert LK, Breiding MJ, Merrick MT, Thompson WW, Ford DC, Dhingra SS, et al. Childhood adversity and adult chronic disease: an update from ten states and the District of Columbia, 2010. Am J Prev Med. 2015;48(3):345-9.

8. Lynch L, Waite R, Davey MP. Adverse chldhood experiences and diabetes in adulthood: support for a collaborative approach to primary care. Contemp Fam Health. 2013:35(4):639-55.

9. Widom CS, Czaja SJ, Bentley T, Johnson MS. A prospective investigation of physical health outcomes in abused and neglected children: new findings from a 30-year follow-up. Am J Public Health. 2012;102(6):1135-44.

10. Scott KM, Von Korff M, Angermeyer MC, Benjet C, Bruffaerts R, de Girolamo $\mathrm{G}$, et al. Association of childhood adversities and early-onset mental disorders with adult-onset chronic physical conditions. Arch Gen Psychiatry. 2011:68(8):838-44.

11. Schussler-Fiorenza Rose SM, Xie D, Stineman M. Adverse childhood experiences and disability in U.S. adults. Phys Med Rehabil. 2014;6(8):670-80.

12. Brown DW, Anda RF, Tiemeier H, Felitti VJ, Edwards VJ, Croft JB, et al. Adverse childhood experiences and the risk of premature mortality. Am J Prev Med. 2009;37(5):389-96.

13. Kelly-Irving M, Lepage B, Dedieu D, Bartley M, Blane D, Grosclaude P, et al. Adverse childhood experiences and premature all-cause mortality. Eur J Epidemiol. 2013;28(9):721-34

14. Zielinski DS. Child maltreatment and adult socioeconomic well-being. Child Abuse Negl. 2009;33(10):666-78.

15. Greenfield EA. Child abuse as a life-course social determinant of adult health. Maturitas. 2010;66(1):51-5.

16. Hayward MD, Gorman BK. The long arm of childhood: the influence of early-life social conditions on men's mortality. Demography. 2004;41(1): 87-107.

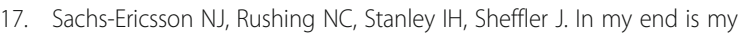
beginning: developmental trajectories of adverse childhood experiences to late-life suicide. Aging Ment Health. 2016;20(2):139-65.

18. National Institute of Diabetes and Digestive and Kidney Diseases (NIDDK). National Diabetes Statistics Report, 2014: NIDDK; 2014. Contract No.: June 13. https://www.niddk.nih.gov/health-information/diabetes/ diabetes-statistics

19. Centers for Disease Control. National diabetes fact sheet, 2011. Atlanta: Department of Health and Human Services; 2011.

20. Centers for Disease Control. National Diabetes Statistics Report, 2017: CDC; 2017. http://www.diabetes.org/assets/pdfs/basics/cdc-statisticsreport-2017.pdf
21. Huang H, Yan P, Shan Z, Chen S, Li M, Luo C, et al. Adverse childhood experiences and risk of type 2 diabetes: a systematic review and metaanalysis. Metab Clin Exp. 2015;64(11):1408-18.

22. Tamayo $\mathrm{T}$, Christian H, Rathmann W. Impact of early psychosocial factors (childhood socioeconomic factors and adversities) on future risk of type 2 diabetes, metabolic disturbances and obesity: a systematic review. BMC Public Health. 2010;10:525.

23. Huffhines $L$, Noser A, Patton SR. The link between adverse childhood experiences and diabetes. Curr Diab Rep. 2016;16(6):54.

24. Maty SC, James SA, Kaplan GA. Life-course socioeconomic position and incidence of diabetes mellitus among blacks and whites: the Alameda County study, 1965-1999. Am J Public Health. 2010;100(1):137-45.

25. Rich-Edwards JW, Spiegelman D, Lividoti Hibert EN, Jun HJ, Todd TJ, Kawachi I, et al. Abuse in childhood and adolescence as a predictor of type 2 diabetes in adult women. Am J Prev Med. 2010;39(6):529-36.

26. Bellis MA, Hughes $K$, Leckenby $N$, Jones $L$, Baban A, Kachaeva M, et al. Adverse childhood experiences and associations with health-harming behaviours in young adults: surveys in eight eastern European countries. Bull World Health Organ. 2014;92(9):641-55.

27. Rehkopf DH, Headen I, Hubbard A, Deardorff J, Kesavan Y, Cohen AK, et al. Adverse childhood experiences and later life adult obesity and smoking in the United States. Ann Epidemiol. 2016;26(7):488-92 e5.

28. Remigio-Baker RA, Hayes DK, Reyes-Salvail F. The relationship of adverse childhood events to smoking, overweight, obesity and binge drinking among women in Hawaii. Matern Child Health J. 2017;21(2):315-25.

29. Danese A, Tan M. Childhood maltreatment and obesity: systematic review and meta-analysis. Mol Psychiatry. 2014;19(5):544-54.

30. Fuemmeler BF, Dedert E, McClernon FJ, Beckham JC. Adverse childhood events are associated with obesity and disordered eating: results from a U.S. population-based survey of young adults. J Trauma Stress. 2009;22(4):329-33.

31. Heerman WJ, Krishnaswami S, Barkin SL, McPheeters M. Adverse family experiences during childhood and adolescent obesity. Obesity (Silver Spring). 2016;24(3):696-702.

32. Husarewycz MN, El-Gabalawy R, Logsetty S, Sareen J. The association between number and type of traumatic life experiences and physical conditions in a nationally representative sample. Gen Hosp Psychiatry. 2014; 36(1):26-32

33. Isohookana R, Marttunen $M$, Hakko H, Riipinen $P$, Riala K. The impact of adverse childhood experiences on obesity and unhealthy weight control behaviors among adolescents. Compr Psychiatry. 2016;71:17-24.

34. Shin SH, Miller DP. A longitudinal examination of childhood maltreatment and adolescent obesity: results from the National Longitudinal Study of adolescent health (AddHealth) study. Child Abuse Negl. 2012;36(2):84-94.

35. Thomas C, Hypponen E, Power C. Obesity and type 2 diabetes risk in midadult life: the role of childhood adversity. Pediatrics. 2008;121(5): e1240-9.

36. Anda RF, Croft JB, Felitti VJ, Nordenberg D, Giles WH, Williamson DF, et al. Adverse childhood experiences and smoking during adolescence and adulthood. Jama. 1999;282(17):1652-8.

37. Ford ES, Anda RF, Edwards VJ, Perry GS, Zhao G, Li C, et al. Adverse childhood experiences and smoking status in five states. Prev Med. 2011; 53(3):188-93.

38. Vander Weg MW. Adverse childhood experiences and cigarette smoking: the 2009 Arkansas and Louisiana behavioral risk factor surveillance systems. Nicotine Tob Res. 2011;13(7):616-22.

39. Anda RF, Whitfield CL, Felitti VJ, Chapman D, Edwards VJ, Dube SR, et al. Adverse childhood experiences, alcoholic parents, and later risk of alcoholism and depression. Psychiatr Serv. 2002;53(8):1001-9.

40. Dube SR, Miller JW, Brown DW, Giles WH, Felitti VJ, Dong M, et al. Adverse childhood experiences and the association with ever using alcohol and initiating alcohol use during adolescence. J Adolesc Health. 2006;38(4):444 e1-10.

41. Kivimaki M, Smith GD, Juonala M, Ferrie JE, Keltikangas-Jarvinen $L$, Elovainio $M$, et al. Socioeconomic position in childhood and adult cardiovascular risk factors, vascular structure, and function: cardiovascular risk in young Finns study. Heart. 2006;92(4):474-80.

42. Lidfeldt J, Li TY, Hu FB, Manson JE, Kawachi I. A prospective study of childhood and adult socioeconomic status and incidence of type 2 diabetes in women. Am J Epidemiol. 2007;165(8):882-9.

43. Maty SC, Lynch JW, Raghunathan TE, Kaplan GA. Childhood socioeconomic position, gender, adult body mass index, and incidence of type 2 diabetes 
mellitus over 34 years in the Alameda County study. Am J Public Health. 2008;98(8):1486-94.

44. Bureau of Labor Statistics. National Longitudinal Survey of Youth, 1979: retention and reasons for noninterview [Washington, D.C. ; 2012 July 16]. 2017.

45. Anda RF, Felitti VJ, Bremner JD, Walker JD, Whitfield C, Perry BD, et al. The enduring effects of abuse and related adverse experiences in childhood. A convergence of evidence from neurobiology and epidemiology. Eur Arch Psychiatry Clin Neurosci. 2006;256(3):174-86.

46. Kerr WC, Williams E, Li L, Lui CK, Ye Y, Greenfield TK, et al. Alcohol use patterns and risk of diabetes onset in the 1979 National Longitudinal Survey of youth cohort. Prev Med. 2018;109:22-7.

47. U.S. Department of Health and Human Services USDoA. Dietary Guidelines for Americans, 2015-2020 Washington, DC. 8th ed; 2015. Available from: Archived by WebCite ${ }^{\oplus}$ at https://health.gov/dietaryguidelines/2015/.

48. Rehm J, Irving H, Ye Y, Kerr WC, Bond J, Greenfield TK. Are lifetime abstainers the best control group in alcohol epidemiology? On the stability and validity of reported lifetime abstention. Am J Epidemiol. 2008;168(8):866-71.

49. Kerr WC, Lui CK, Williams E, Ye Y, Greenfield TK, Lown EA. Health Risk Factors Associated with Lifetime Abstinence from Alcohol in the 1979 National Longitudinal Survey of youth cohort. Alcohol Clin Exp Res. 2017; 41(2):388-98.

50. Centers for Disease Control and Prevention. Defining Adult Overweight and Obesity Atlanta, GA 2018. Available from: https://www.cdc.gov/obesity/ adult/defining.html.

51. Chapman DP, Whitfield CL, Felitti VJ, Dube SR, Edwards VJ, Anda RF. Adverse childhood experiences and the risk of depressive disorders in adulthood. J Affect Disord. 2004:82(2):217-25.

52. Dong M, Anda RF, Felitti VJ, Williamson DF, Dube SR, Brown DW, et al. Childhood residential mobility and multiple health risks during adolescence and adulthood: the hidden role of adverse childhood experiences. Arch Pediatr Adolesc Med. 2005;159(12):1104-10.

53. Dube SR, Anda RF, Felitti VJ, Chapman DP, Williamson DF, Giles WH. Childhood abuse, household dysfunction, and the risk of attempted suicide throughout the life span: findings from the adverse childhood experiences study. JAMA. 2001;286(24):3089-96.

54. Dube SR, Felitti VJ, Dong M, Chapman DP, Giles WH, Anda RF. Childhood abuse, neglect, and household dysfunction and the risk of illicit drug use: the adverse childhood experiences study. Pediatrics. 2003;111(3):564-72.

55. Hillis SD, Anda RF, Felitti VJ, Marchbanks PA. Adverse childhood experiences and sexual risk behaviors in women: a retrospective cohort study. Fam Plan Perspect. 2001;33(5):206-11.

56. Singer JD, Willett JB. It's about time: using discrete-time survival analysis to study duration and the timing of events. J Educ Stat. 1993;18:155-95.

57. Lammi N, Taskinen O, Moltchanova E, Notkola IL, Eriksson JG, Tuomilehto J, et al. A high incidence of type 1 diabetes and an alarming increase in the incidence of type 2 diabetes among young adults in Finland between 1992 and 1996. Diabetologia. 2007;50(7):1393-400.

58. Holst C, Becker U, Jorgensen ME, Gronbaek M, Tolstrup JS. Alcohol drinking patterns and risk of diabetes: a cohort study of 70,551 men and women from the general Danish population. Diabetologia. 2017;60(10):1941-50.

59. Carlsson S, Hammar N, Grill V, Kaprio J. Alcohol consumption and the incidence of type 2 diabetes: a 20-year follow-up of the Finnish twin cohort study. Diabetes Care. 2003;26(10):2785-90.

60. Baliunas DO, Taylor BJ, Irving H, Roerecke M, Patra J, Mohapatra S, et al. Alcohol as a risk factor for type 2 diabetes: a systematic review and metaanalysis. Diabetes Care. 2009;32(11):2123-32.

61. Knott C, Bell S, Britton A. Alcohol consumption and the risk of type 2 diabetes: a systematic review and dose-response meta-analysis of more than 1.9 million individuals from 38 observational studies. Diabetes Care. 2015;38(9):1804-12.

62. Rasouli B, Ahlbom A, Andersson T, Grill V, Midthjell K, Olsson L, et al. Alcohol consumption is associated with reduced risk of type 2 diabetes and autoimmune diabetes in adults: results from the Nord-Trondelag health study. Diabet Med. 2013;30(1):56-64.

63. Knott CS, Britton A, Bell S. Trajectories of alcohol consumption prior to the diagnosis of type 2 diabetes: a longitudinal case-cohort study. Int J Epidemiol. 2018;47(3):953-65.

64. Pan A, Wang Y, Talaei M, Hu FB. Relation of smoking with Total mortality and cardiovascular events among patients with diabetes mellitus: a metaanalysis and systematic review. Circulation. 2015;132(19):1795-804.
65. Maddatu J, Anderson-Baucum E, Evans-Molina C. Smoking and the risk of type 2 diabetes. Transl Res. 2017;184:101-7.

66. Sliwinska-Mosson M, Milnerowicz $\mathrm{H}$. The impact of smoking on the development of diabetes and its complications. Diab Vasc Dis Res. 2017; 14(4):265-76.

67. Pervanidou P, Bastaki D, Chouliaras G, Papanikolaou K, Kanaka-Gantenbein C, Chrousos G. Internalizing and externalizing problems in obese children and adolescents: associations with daily salivary cortisol concentrations. Hormones. 2015;14(4):623-31.

68. Aparicio E, Canals J, Arija V, De Henauw S, Michels N. The role of emotion regulation in childhood obesity: implications for prevention and treatment. Nutr Res Rev. 2016;29(1):17-29.

69. Glover DA, Stuber M, Poland RE. Allostatic load in women with and without PTSD symptoms. Psychiatry. 2006;69(3):191-203.

70. Pervanidou P. Chrousos GP. Stress and obesity/metabolic syndrome in childhood and adolescence. Int J Pediatr Obes. 2011;6(Suppl 1):21-8.

71. Centers for Disease C, Prevention. Prevalence of diabetes among Hispanics--selected areas, 1998-2002. MMWR Morb Mortal Wkly Rep. 2004;53(40):941-4.

72. Gaskin DJ, Thorpe RJ Jr, McGinty EE, Bower K, Rohde C, Young JH, et al. Disparities in diabetes: the nexus of race, poverty, and place. Am J Public Health. 2014;104(11):2147-55.

73. Williams DR, Collins C. Racial residential segregation: a fundamental cause of racial disparities in health. Public Health Rep. 2001;116(5):404-16.

74. Franco M, Diez Roux AV, Glass TA, Caballero B, Brancati FL. Neighborhood characteristics and availability of healthy foods in Baltimore. Am J Prev Med. 2008;35(6):561-7.

75. Greenfield TK, Martinez P, editors. Alcohol as a risk factor for chronic disease: raising awareness and policy options. Washington, DC: APHA Press; 2017.

76. Golding J. Sexual assault history and limitations in physical functioning in two general population samples. Res Nurs Health. 1996b;19:33-44.

77. Leserman J, Drossman DA, Li Z, Toomey TC, Nachman G, Glogau L. Sexual and physical abuse history in gastroenterology practice: how types of abuse impact health status. Psychosom Med. 1996;58:4-15.

78. Drossman DA, Leserman J, Nachman G, Zhiming L, Gluck H, Toomey TC, et al. Sexual and physical abuse in women with functional or organic gastrointestinal disorders. Ann Intern Med. 1990;113:828-33.

79. Wade R Jr, Becker BD, Bevans KB, Ford DC, Forrest CB. Development and evaluation of a short adverse childhood experiences measure. Am J Prev Med. 2017;52(2):163-72.

80. VanderWeele TJ, Vansteelandt S. Odds ratios for mediation analysis for a dichotomous outcome. Am J Epidemiol. 2010;172(12):1339-48.

81. VanderWeele TJ, Vansteelandt S. Mediation analysis with multiple mediators. Epidemiol Methods. 2014;2(1):95-115.

82. Merlotti C, Morabito A, Ceriani V, Pontiroli AE. Prevention of type 2 diabetes in obese at-risk subjects: a systematic review and meta-analysis. Acta Diabetol. 2014;51(5):853-63.

83. Fruchter $\mathrm{O}$. Prevention of type 2 diabetes mellitus by changes in lifestyle. $\mathrm{N}$ Engl J Med. 2001;345(9):696 author reply -7 .

84. Fodor JG, Adamo KB. Prevention of type 2 diabetes mellitus by changes in lifestyle. N Engl J Med. 2001;345(9):696 author reply -7.

85. Tuomilehto J, Lindstrom J, Eriksson JG, Valle TT, Hamalainen H, llanneParikka P, et al. Prevention of type 2 diabetes mellitus by changes in lifestyle among subjects with impaired glucose tolerance. N Engl J Med. 2001; 344(18):1343-50.

86. National Institute of Diabetes and Digestive and Kidney Diseases (NIDDK). Choose More than 50 Ways to Prevent Type 2 Diabetes website: NIDDK and the National Diabetes Education Program; 2018 [NIH Publication No. 125487]. Available from: https://www.niddk.nih.gov/health-information/ diabetes/overview/preventing-type-2-diabetes/50-ways.

87. Hurt TR, Seawell AH, Cutrona C, O'Connor MC, Camp RD, Duran R, et al. Black Women's recommendations for developing effective type 2 diabetes programming. Glob Qual Nurs Res. 2017;4:2333393617715335.

88. Cusi K, Ocampo GL. Unmet needs in Hispanic/Latino patients with type 2 diabetes mellitus. Am J Med. 2011;124(10 Suppl):S2-9.

\section{Publisher's Note}

Springer Nature remains neutral with regard to jurisdictional claims in published maps and institutional affiliations. 